\title{
Skipping Rope and Double Dutch Lessons for Elementary School Students
}

\author{
Didin Budiman*, Dian Budiana, Agus Mahendra, Ricky Wibowo, Rani Meidiati, M Rizki Akbari \\ Department of Sport Education, Faculty of Sport and Health Education \\ Universitas Pendidikan Indonesia \\ Bandung, Indonesia \\ *didinbudiman1974@upi.edu
}

\begin{abstract}
The purpose of this study was to measure the children response to newly introduced lesson contents they never experienced before; they are skipping rope and double dutch. Preceded by introducing these skipping rope and Double Dutch skills to PE teachers through a short training, then all teachers are assigned to start teaching them to their children in school through PE lesson. On the other period, teams of observers were assigned to monitor the quick yield of the learning at schools, both in skill acquisition and the enthusiasm of children over the skills being introduced. The observation data then be analyzed through a simple procedure and the results were abstracted into the calculated format, to withdraw the conclusion. The result, much to our surprise, was so promising, since the children were so enthusiastic to these new activities. This result has ruined the old perception that children would have only interested in to formal sport skills activities. This could have happened simply that children also would also be so attracted by the new challenging activities.
\end{abstract}

\section{Keywords-skipping rope; double dutch; basic movements}

\section{INTRODUCTION}

The Content of Physical Education lesson in Indonesia has been dominated by the sports-based content [1]. Given the fact that this has been going on for many decades, it seemed that it has been accepted as taken for granted. This includes the learning PE in Primary Schools (Elementary School), where children are encouraged or "forced" to learn formal sports without being provided by any other form of modification as alternative [2]. Teaching PE subject then are mostly related and directed to the basic techniques acquisition of a particular sport, and consequently, the learning equipment to be utilized are mostly those meeting the sport standards.

Therefore, if we look a bit closer at the PE lesson conducted at most elementary schools, we all could notice that the learning process did not much differ from what has been taught in the level of junior or senior high schools. The equipment to be provided relatively the same and the movement tasks chosen by the teacher are also similar; the only difference is in the size of the students involved within it. Grade 1 or grade 2 of elementary school children are arbitrarily required to learn basic techniques of, say, volleyball or basketball, similar to those played by the older student in their mature level. This condition will certainly make it very difficult for them to learn the movements and skills taught, because even for the 6th grader children, those skills should not as well be considered appropriate, in terms of the level of difficulty and the size of the equipment [3].

Through a simple trace to the school, especially through brief dialogues and light discussion with PE teachers, there emerged one worrying conclusion that what they teach and how they teach was the only they know and they simply claimed that all they did has been officially in accordance to the formally mandated in the 2013 National Curriculum [4].

In fact, the 2013 curriculum content and syllabus have accommodated 6 activities into its scope of learning, namely Basic Movement Pattern activities, games and sports activities, fitness activities, gymnastic activities, rhythmic activities, and aquatic activities. Seen from that perspective, it is broadly possible that the lesson could immerse a broader content such non-sport activities as basic movement involving locomotor, non-locomotor and manipulative skills and other rhythmical activities as dances and simple games.

Unfortunately, even though the scope of curriculum has flexible room in accommodating efforts to introduce basic movement components to children [5]. The syllabus that accompanying curriculum has always deliberately connected all the basic movement with games and sports [6]. As the result, teacher very often consider all the basic movement as part of sports and games. As the consequence, PE teachers will never able to stay away from teaching sports to elementary school children, with only a slight effort in modifying it [1].

$\mathrm{PE}$ in Indonesia, as many experts repeatedly argued, will never be able to depart anywhere; not towards the psychomotor and cognitive development, let alone to the development of affective domain that currently is widely expected to influence or contribute to the development of moral and spiritual aspects [7]. A further concern about this recent situation is that children and adolescents are horrifyingly felt encouraged adopting passive lifestyle. As reported by many research in many countries, that the trend of screen time of children and adolescents are dramatically increasing [8], which strongly evidenced by the increasing number of children spending their time in front of television, computer, or busy with smart phone 
gadgets simply for playing games. As a result, the amount and duration of time for physical activity is greatly decreased [9].

Opinion of the experts encouraged the research team to see whether the PE teachers in Bandung city have sufficient competencies needed to change the alarming situation above? It was concluded that most of PE teachers did not have the awareness and even the ability to find alternative solutions in solving the aforementioned problem. It is readily assumed that they need necessary helps to decide proactively toward the newly designed program for PE. The teachers have to be helped in order to gain their knowledge and competencies related to start practicing appropriate content of physical education material for elementary students, as one the content knowledge collection [10,11].

From the line of thinking formulated in the beginning of this manuscript, it is deemed necessary to reformulate steps to improve the performance of the PE teachers in Bandung as a whole. From the researcher point of view, this recent situation constitutes of established features brought up by a strongly manifested system that has been implemented in the long run. We need to employ a serious effort to change it and will of course certainly requires two-way corrective steps; on one hand, we need to improve the existing conditions in real action setting, and on the other hand, we need to improve the appropriate system, including the $\mathrm{PE}$ teacher preparation program, including the physical education teacher education (PETE) curriculum at the study program level, efforts to review the applicable curriculum in schools, and giving interventions to improve school systems and policies, especially in the procurement of $\mathrm{PE}$ learning equipment.

However, to reduce the complexity and intricacy of the currently developing problems, a number of strategic steps are needed, including organizing a program "Training and Socialization of Skipping Rope Learning Content for Elementary School Teachers in Bandung." This training is seen as an important program, especially in dealing with providing useful insights for PE teachers who are currently in their positions, so that it can be used in line with their assignments when becoming guiding teachers of in partner schools. To make this preliminary step convincing in terms of the effect, we conducted a simple observation to all schools participating in in the program, especially in seeking the response of children to the new activities, skipping rope and double dutch, in the perspective of their enthusiasm [12].

\section{METHOD}

This research is actually a simple inquiry to the results of the application program, which is preceded by the gradual implementation of an idea, which is then monitored at the end of program, through changes and improvements in student behavior as the final goal of action research. This type of research can be categorized as collaborative action research, where researchers become a leading action researcher's team, providing tasks for teachers to change their teaching methods in applying new subject matter to the students [13]. The researcher then monitors the progress of students' learning outcomes brought about by the teachers who are involved in this collaboration program.

\section{A. Settings of Action Implementation}

This research program is designed to involve teachers in a training program. The training is certainly based on efforts to apply the field area currently controlled by program proponents and colleagues who have concerns to change existing conditions, namely the rigidity of lesson content of PE. The training content provided is one of the typical attractive content, namely skipping rope skills as one of the potential subjects used in PE learning [14-17].

In the research team's viewpoint, this content will be very well mastered by the teacher and latter be developed and implemented in PE lessons, as well as in co-curricular and extra-curricular programs. This content can be learned by all children at the same time and in a relatively short time entertain and encourage children to develop physical fitness [18], especially in the components of cardiovascular endurance and leg power $[19,20]$.

In addition, the movement can be arranged into a unique movement while they are in pairs or groups [21], which certainly has potential to develop students' social skills, beside its movements are attractive enough for both the doer and those who observe. If many schools have adopted this attractive rope jumping skill, it will be an interesting challenge for school to organize competition in school level and in other community level.

To maximize this training program for teacher, and to maintain continuous cooperation between study program and teachers, the training program also introduced the application of Classroom Action Research and several PE learning models. For the purpose of continuous monitoring program, the participants were assigned to apply all those training content in schools.

\section{B. Target of Participants}

The audience target of this program is the PE teacher in Bandung city from partner schools. There are around 12 elementary schools got involved in this program, both public and private schools. With the average number of 2 teachers from each school, the participants of this program will be around 24 to 30 people.

The current condition of the target audience is certainly those who have not mastered this basic movement skipping rope skills, they are also teachers who are more oriented to PE with strong advocate to sports. The training target is not only to improve their acquisition in terms of skills, but also be directed to encourage teachers to capable of developing a sound and various teaching materials, no longer limited to formal sports.

\section{Target of Research}

The end output of this program is the increased of teachers skills and abilities in teaching practices with offering more varied contents for elementary students. For that purpose all teachers are encouraged to set an agreement so that all participating teachers can develop basic rope jumping skills in their schools, including to reprogram the physical fitness levels of students at school [22]. The next target, this program is as well directed at embracing all schools in Bandung city and all 
neighboring districts. In addition, through the expertise owned by the study program, there will be strong urge to create a festival and rope jump championship in Indonesia. But for the purpose of this initial stage, the result will be represented by the level acquisition of jumping rope skill of the children who were taught by the participating teachers.

\section{Measurement and Data Processing Techniques}

In the period of one month after the training, the researcher team formed a monitoring team to conduct routine observations to schools to assess changes or mastery of rope jumping skills of children. The instruments are the observation format elaborating 3 main aspects of rope jumping skills, which include the implementation of a rope rotation (technique), the frequency of rotation or the number of movements that students able to do, and the ability of children in variations making. To anticipate higher progress, the instrument also includes valuing the level of skills when used in pairs, teams, and double dutch [23].

Scores are entered into the observation format, categorized into five categories, namely the scale of 1 to 5 . Scale 1 is a skill that is still very rough, not yet mastered, and there are still many unpleasant movements, scale 2 is the movement has shown mastery at a smooth level, but brief time; scale 3 includes the skills category that has been very smooth, coordinated and demonstrating the ability to do variations; scale 4 is a category that has smooth, well manner and high mastery in variation movements; while scale 5 is a very high skill category so that it can be done with high frequencies, high speed and high accuracy, and can be done in several different body positions.

Whereas to measure students' enthusiasm in learning this jump rope skills, a special form is modified from Dale A. Ulrich with the following provisions: children are given a score of 1 for an enthusiastic and receptive display of assignments, and given 0 for the number of reasons and real reluctance shown by the child [24]. There is no partial score. The filling of the score is carried out in each episode of learning time, and each time the teacher offers movement assignments or increases the level of difficulty in their learning. High scores show better performance than lower scores. In this way, the evaluation process is carried out by comparing descriptive ratings with the Standard Score of the Subtest in tables and percentiles can be determined using the available tables.

\section{RESUltS AND DisCUSSION}

\section{A. Results} of:

This study elicited several sub-aspects of results, consisting

1) Data on the number of schools having implemented jumping rope learning in the form of Classroom Action Research (CAR), and applying cooperative learning models, with the aim of developing mastery of rope jumping skills and improving physical fitness of students: Of the 24 teachers who attended the training program, 15 teachers stated that they had once and several times implemented cooperative models even though they have not intended to conduct classroom action research. 10 teachers stated that they had entered the stage of developing Classroom Action Research, and had entered the data processing stage. The rests are still in the stage of planning and still trying to find solution to provide children with the rope (equipment) needed.

Of those who have initiated the learning process, some teachers already made the evaluation program with conducting the measurement test for the children. Most teachers opted to choose the upper grades children to become the target of development, comprising of 5 and 6 graders. None of the teacher already made a brave decision with ordering rope equipment, but the only way to make them available was to ask all children bring along the rope available at home.

2) Data on the ability or skills of rope jumping from those who are tested with the task of performing rope jumping skills for three occasions and carried out during and as many repetitions as possible. Of the 10 teachers who stated that they had applied the cooperative learning model in jumping rope teaching content, the result of the processed data made up as the followings:

TABLE I. PERCENTAGE OF CHILDREN'S MASTERY OF SKIPPING ROPE

\begin{tabular}{|l|l|}
\hline \multicolumn{1}{|c|}{ Percentage } & \multicolumn{1}{c|}{ Categories of Children } \\
\hline $160 / 40 \%$ & excellent category \\
\hline $40 / 10 \%$ & good category \\
\hline $180 / 45 \%$ & medium category \\
\hline $20 / 5 \%$ & poor category \\
\hline
\end{tabular}

3) The data on children enthusiasm also shows these results:

TABLE II. PERCENTAGE OF CHILDREN’s ENTHUSIASM PRACTICING SKIPPING ROPE

\begin{tabular}{|l|l|}
\hline \multicolumn{1}{|c|}{ Percentage } & \multicolumn{1}{c|}{ Categories of Children } \\
\hline $280 / 70 \%$ & Very enthusiastic \\
\hline $100 / 25 \%$ & Good enthusiasm \\
\hline $00 / 0 \%$ & Medium category \\
\hline $20 / 5 \%$ & Poor enthusiasm category \\
\hline
\end{tabular}

\section{B. Discussion}

Noting the results above, it should be grateful that the training program for the development of jumping rope and double dutch content had contributed to the increase of teaching content repertoire available for children, and the implementation program was seen positively by students, since the majority of students liked the learning activities very much and showed high enthusiasm in the whole process of learning [23].

Regarding to the small numbers of teachers who have been in the implementation process, it is indeed regretted but all could be understood given the fact that not all school are ready with the available equipment. What we are afraid about is that they will soon forget the movements they learned and surely they will be reluctant to implement it in latter time. The researcher team doesn't even have any ability to change the 
situation, but suggested that they could ask the children to bring along from their home, as long as it could be permitted by regulation.

The level of mastery of the students on rope jumping skills must be seen as a positive thing. The number of students who are quite mastering the movement can become one evident that students have good basic ability to learn new movement. It is believed that students can perform exercises or jump rope skills anywhere outside the formal lesson, so that they benefited from the frequency of doing the skills [25].

One issue that must be admitted that the jumping rope movement is a kind that can be conducted easily without necessitate certain conditions, where it does not require wide space, does not needs any partner to support, and also can be done at any time. This certainly made most children able to repeat in high frequency as long as they have the rope. Thus, it is easy for them to comply with the principle of training, that skill can only be mastered by high frequency of repetition to become skillful mover [3].

On the other hand, teacher can continually encourage all students to take advantage of the skills in playing ropes to be continuously further directed at improving students' physical fitness. With additional tasks designed by the teacher in form of independent working out, students will certainly build a good level of physical fitness. The logic behind it is that students have to master and enjoy the activity, and children's pleasure on doing it will become an effective tool to reduce children's screen time outside the school [8].

All the above issues are considered in accordance with the main topic of this study namely measuring students' enthusiasm for this simple but effective teaching material [26]. It simply because that the jumping rope is one of the attractive movements in the eyes of students. Thus, it will not become a major obstacle to making rope jumping as a tool to develop "eager to move" attitudes and positive active behaviors as a vehicle to building the movement culture and active life style in elementary school students. In that perspective, the skipping rope content deserves to be categorized as having good precondition as "intrinsically attractive" content. We think we must try very hard to realize and develop one effective strategy in fighting one alarming symptom hitting the modern society, especially the younger generation including children in our schools, namely the symptoms of increasing screen time in this modern era [27]. The strategy is called "program to get our kid moving" through skipping rope and double dutch movement in schools.

\section{CONCLUSION}

The program of introducing the skipping rope and double dutch activities to elementary school children is possibly promising, in terms that majority of children are eager and curious of knowing and able to acquire the skill. This is a good sign that the activities can be proposed to the national curriculum center as the motor task that must be listed as a proper subject in the PE curriculum. With this result, it is also promising that all schools in Indonesia will have common policy regarding the apparatus and the level of children physical activities.

\section{ACKNOWLEDGMENT}

There are many persons were involved in this study. We would be very much excited to take this section to extent our deep appreciation to those who made the study possible to be accomplished: cooperating teachers from all the partner schools, and especially all the partner school principals.

\section{REFERENCES}

[1] A. Mahendra, "Telaah Kritis terhadap Program PGPJ (Pendidikan Guru Pendidikan Jasmani) di Indonesia," ATIKAN, vol. 4(2), 2014.

[2] A.S. Ha, A.C. Wong, R.K. Sum, and D.W. Chan, "Understanding teachers' will and capacity to accomplish physical education curriculum reform: The implications for teacher development," Sport, Education and Society, vol. 13(1), pp. 77-95, 2008.

[3] P. Iserbyt, P. Ward, and W. Li, "Effects of improved content knowledge on pedagogical content knowledge and student performance in physical education," Physical Education and Sport Pedagogy, vol. 22(1), pp. 71$88,2017$.

[4] Indonesian Ministry of Education and Culture. Praturan Menteri Pendidikan dan Kebudayaan Republik Indonesia Nomor 24 Tahun 2016 Tentang Kompetensi Inti dan Kompetensi Dasar Pelajaran Pada Kurikulum 2013.

[5] J.G. Ross, R.R. Pate, C.B. Corbin, L.A. Delpy, and R.S. Gold, "What is going on in the elementary physical education program?," Journal of Physical Education, Recreation \& Dance, vol. 58(9), pp. 78-84, 1987.

[6] J. Mandigo, and N. Holt, "Reading the game: Introducing the notion of games literacy," Physical and Health Education Journal, vol. 70(3),pp. 4-10, 2004.

[7] R. Bailey, K. Armour, D. Kirk, M. Jess, I. Pickup, and R. Sandford, "The educational benefits claimed for physical education and school sport: an academic review," Research papers in education, vol. 24(1), pp. 1-27, 2009.

[8] M.K. Merga and R. Williams, "The role of health educators in mitigating health risk from increasing screen time in schools and at home," Asia-Pacific Journal of Health, Sport and Physical Education, vo. 7(2), pp. 157-172, 2016

[9] M. del-Carmen Ortega-Navas, "The use of new technologies as a tool for the promotion of health education," Procedia-Social and Behavioral Sciences, vol. 237, pp. 23-29, 2017.

[10] P.A. Hastie, "Revisiting the national physical education content standards: What do we really know about our achievement of the physically educated/literate person?," Journal of Teaching in Physical Education, vol. 36(1), pp. 3-19, 2017.

[11] V.H. Stiles and W.H. Katene, "Improving physical education studen teachers' knowledge and understanding of applied biomechanical principles through peer collaboration," Physical education and sport pedagogy, vol. 18(3), pp. 235-255, 2013

[12] T.H. Hull, E. Hasmi, and N. Widyantoro, “"'Peer” educator initiatives for adolescent reproductive health projects in Indonesia," Reproductive Health Matters, vol. 12(23), pp. 29-39 2004.

[13] E. Sherry, N. Schulenkorf, E. Seal, M. Nicholson, and R. Hoye, "Sportfor-development: Inclusive, reflexive, and meaningful research in lowand middle-income settings," Sport Management Review, vol. 20(1), pp. 69-80, 2017.

[14] A.S. Ha, C. Lonsdale, J.Y. Ng, and D.R. Lubans, "A school-based rope skipping program for adolescents: Results of a randomized trial," Preventive medicine, vol. 101, pp. 188-194, 2017.

[15] S.G. Karungaru, K. Matsuura, and N. Gotoda, "Feature Tracking using Particle Filter in Rope Skipping for Gross Motor Skill Development" Proceedings of 2nd ICKE2016, 2016.

[16] H. Kawano, F. Motegi, T. Ando, Y. Gando, M. Mineta, S Numao, ... and M. Higuchi, "Appetite after rope skipping may differ between males and females," Obesity research \& clinical practice, vol. 6(2), pp. e121e127, 2012. 
[17] O.K. Ham, K.M. Sung, B.G. Lee, H.W. Choi, and E.O. Im, "Transtheoretical model based exercise counseling combined with music skipping rope exercise on childhood obesity," Asian nursing research, vol. 10(2), pp. 116-122, 2016.

[18] C.C. Chen, and S.Y. Lin, "The impact of rope jumping exercise on physical fitness of visually impaired students," Research in developmental disabilities, vol. 32(1), pp. 25-29, 2011

[19] M.G. Hodges, P.H. Kulinna, H. Van Der Mars, and C. Lee, "Knowledge in action: Fitness lesson segments that teach health-related fitness in elementary physical education," Journal of teaching in physical education, vol. 35(1), pp. 16-26, 2016.

[20] J. McNamee, G.L. Timken, S.C. Coste, T.L. Tompkins, and J. Peterson, "Adolescent girls' physical activity, fitness and psychological wellbeing during a health club physical education approach" European Physical Education Review, vol. 23(4), pp. 517-533, 2017.

[21] K.L. Thorndahl and S. Ravn, "Expert tool use: a phenomenological analysis of processes of incorporation in the case of elite rope skipping," Sport, ethics and philosophy, vol. 10(3), pp. 310-324, 2016.

[22] P.H. Kulinna, K. Scrabis-Fletcher, S. Kodish, S. Phillips, and S. Silverman, "A decade of research literature in physical education pedagogy" Journal of Teaching in Physical Education, vol. 28(2), pp. 119-140, 2009.

[23] C. Wirszyla, "Double Dutch for All: Keep rope jumping alive for the entire school year!," Strategies, vol. 11(6), pp. 8-10, 1998.

[24] M. Kaur, S.M. Srinivasan, and A.N. Bhat, "Comparing moto performance, praxis, coordination, and interpersonal synchrony between children with and without Autism Spectrum Disorder (ASD)," Research in developmental disabilities, vol.72, pp. 79-95, 2018.

[25] D.G. Liebermann, L. Katz, M.D. Hughes, R.M. Bartlett, J. McClements, and I.M. Franks, "Advances in the application of information technology to sport performance," Journal of sports sciences, vol. 20(10), pp. 755769, 2002.

[26] A. Bosco, "Physical education and fostering relationships," International Journal of Children's Spirituality, vol. 18(1), pp. 92-102, 2013.

[27] L. Haerens, D. Kirk, G. Cardon, amd I. De-Bourdeaudhuij, "Toward the development of a pedagogical model for health-based physical education," Quest, vol. 63(3), pp. 321-338, 2011. 